\title{
Reconfiguration of a Wind Turbine with Hydrostatic Drivetrain to Improve Annual Energy Production
}

\author{
Majid Deldar, Afshin Izadian, Senior Member IEEE, and Sohel Anwar, Member, IEEE \\ Energy Systems and Power Electronics Laboratory \& Mechanical Engineering Department \\ Purdue School of Engineering and Technology, Indianapolis, USA \\ \{mdeldar\},\{aizadian\}, \{soanwar\}@iupui.edu
}

\begin{abstract}
Hydrostatic transmission systems (HTS) have shown potential in replacing gearbox in conventional wind turbines. However, the general perception about these systems is that they suffer from low efficiencies, specifically at low wind speeds. This paper presents a novel technique that can improve the annual energy production (AEP) beyond that of a conventional wind turbine. By optimizing the operating conditions and the design of the wind turbine, the performance and efficiency of a HTS can be improved. A side-by-side comparison with the conventional wind turbines is provided to highlight the benefits of the proposed methodology. One of the findings of this research is that, rotor, hydrostatic pump, motor and their operations' planning must be optimized together to achieve higher AEP. The reconfigured turbines are shown to provide up to 8 percent $A E P$ increase for a $750 \mathrm{~kW}$ plant and up to 10 percent increase for $1500 \mathrm{~kW}$ plants using the proposed drivetrain configurations.
\end{abstract}

Keywords-Power coefficient; Efficiency; Annual Energy Production; Hydrostatic transmission

\section{INTRODUCTION}

By 2030, the wind energy is planned to cover significant share of the US energy [1]. Improving the performance of wind turbines facilitates higher energy production. Conventionally, a gearbox transmits the power from high torque-low speed rotor to a low torque-high speed generator. This wind turbine subassembly is heavy and expensive with long failure downtimes $[2,3]$. It requires power electronics to adjust the voltage and frequency of the generator. However, Hydrostatic Transmission System (HTS) can be an alternative power transmission technique. It is comprised of a fixed displacement hydraulic pump coupled with the rotor within the nacelle and a variable displacement motor coupled with a generator on ground level. Controlling displacement of the motor adjusts the transmission ratio, thus the generator rotates at a synchronous speed coupled with the grid frequency while the hydraulic pump speed varies with wind speed to track optimum operating points. The efficiency of HTS wind turbines are studied in $[4,5]$ where the minimum efficiency of the transmission occurs at low wind speed. Schmitz et al [6] suggested having two hardware configurations, one configuration that has high efficiency for low speed and one configuration for high wind. However, it was noted that the hardware switching imposes large breaking torque on hydrostatic components. Dutta et al [7] suggested that to compensate for lower efficiencies, an auxiliary pump can be used to store pressurized flow in an accumulator that will be released when wind speed is slightly lower than rated speed. This approach can increase AEP, but still the issue of low efficiency values at low wind speeds has not been addressed. In this paper, a novel approach in maximizing the efficiency of a wind turbine (WT) with hydrostatic transmission system is investigated. The design of a WT is optimized to achieve higher efficiencies resulting in an increased annual energy production (AEP). The AEP of the optimized WT is simulated and compared with that of a conventional geared WT.

\section{Hydrostatic TRANSMission SyStem FOR WIND TURBINE APPLICATIONS}

Hydraulic pumps and motors are the key components of a hydrostatic circuit for power transmissions. The turbine operates as the prime mover of a hydrostatic pump to provide high pressure flow to the circuit. At the motor side, the generator torque imposes load on the hydraulic motor shaft which induces pressure between the pump outlet and the motor inlet. Pumps and motors are structurally similar since they convert mechanical energy to hydrostatic energy and vice versa. To investigate the efficiency of a pump or a motor the steady state force balances can be written as follows [8-10],

$T_{\text {load }}=D_{m} P-C_{v m} D_{m} \omega_{m}-C_{f m} D_{m} P-T_{C m}$

$Q_{m}=D_{m} \omega_{m}+K_{S m} P$

where, $P$ is the pressure, $T_{\text {load }}$ is the generator load torque, $D_{m}$ and $\omega_{m}$ are the motor displacement and speed respectively. $C_{v m}$ and $C_{f m}$ are viscous drag and coulomb friction coefficient respectively, and $T_{C m}$ is the breakaway torque. The term $D_{m} P$ in (1) is the driving torque of the motor and the other three terms show mechanical losses. In addition, a portion of fluid slips from high pressure chamber to the low pressure chamber. Therefore, the actual required flow rate slightly differs from the theoretical value. This volumetric loss within a motor is explained in (2). In this equation, $Q_{m}$ is the actual flow of motor and $K_{S m}$ is the slippage coefficient of motor. Similarly for the pump, mechanical loss and volumetric loss [8-10] are written as follows:

$$
\begin{aligned}
& T_{\text {rotor }}=D_{P} P+C_{V p} D_{P} \omega_{\text {rotor }}+C_{F p} D_{p} P+T_{C p} \\
& Q_{p}=D_{P} \omega_{p}-K_{S p} P
\end{aligned}
$$

where, $T_{\text {rotor }}$ is the torque of the turbine rotor, $D_{p}$ and $\omega_{P}$ are pump displacement and speed respectively. pump displacement, $C_{v p}$ and $C_{f m}$ are viscous drag and coulomb friction coefficient respectively and $T_{C p}$ is the breakaway torque. In (4), $Q_{p}$ is the actual flow of the pump and $K_{S p}$ is the slippage coefficient. 


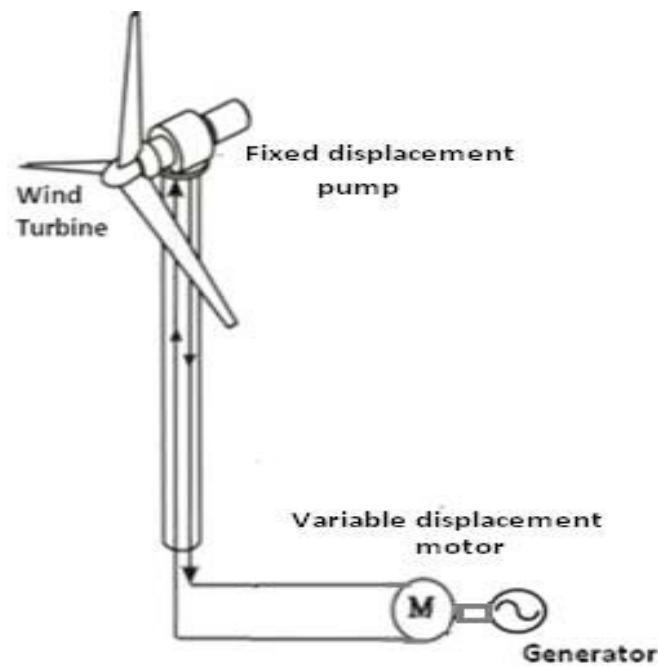

Fig. 1 Schematic of a wind turbine utilizing HTS

\section{REGIONAL EFFICIENCY OPTIMIZATION}

From motor and pump models, Equation 1-4, it can be seen that the energy conversion efficiency is influenced by the mechanical and volumetric losses. The mechanical losses are viscous drag, coulomb friction and breakaway torque. Viscous drag is caused by the fluid shear between two parts having relative motion. The coulomb friction is due to contact between two metal surfaces such as bearing and shaft and the breakaway torque is caused by sealing friction. Overall efficiency of a pump and a motor including mechanical and volumetric losses [8-10] are formulated as follows:

$$
\begin{gathered}
\eta_{p_{\text {overall }}}=\eta_{P \text { mech. }} . \eta_{P \text { vol. }}=\frac{1-\frac{K_{S p}}{A}}{1+A C_{v p}+C_{f p}+\frac{T_{c p}}{D_{p} P}}, A=\frac{\mu \omega_{p}}{P} \\
\eta_{m \text { overall }}=\eta_{M \text { mech. }} . \eta_{M \text { vol. }}=\frac{1-B C_{v m}-C_{f m}-\frac{T_{c m}}{D_{m} p}}{1+\frac{K_{S m}}{B}}, B=\frac{\mu \omega_{m}}{P}
\end{gathered}
$$

where $\eta_{\text {Poverall }}$ is the overall efficiency of a pump, $\eta_{\text {Pmech. }}$ and

$\eta_{P \text { vol. }}$ are mechanical efficiency and volumetric efficiency of the pump. Similar notations are used for motor efficiencies in equation (6). In these formulations, efficiencies are defined as functions of dimensionless factors A and B. $\mu$ is the dynamic viscosity of fluid.

Figure 2 illustrates generic trend of pump and motor efficiency as a function of factor A or B.

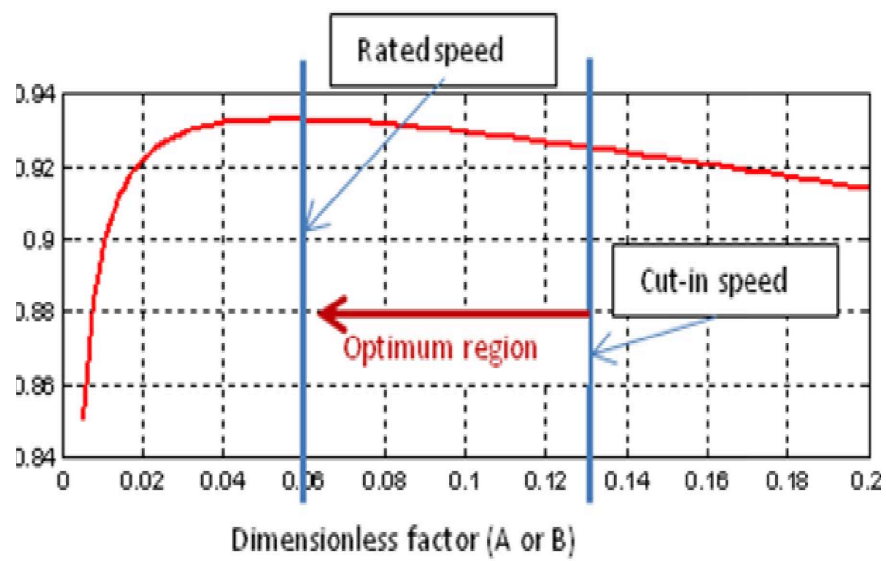

Fig. 2 General trend of efficiency variation for a pump or a motor

The efficiency is affected by rotational speed and pressure variations. For applications where operating conditions, pressure and speed, do not vary widely, the hydrostatic transmission is designed to have the best efficiency. However, due to intermittent nature of wind, the operating conditions change widely, thus, it is not possible to continuously operate the system at its maximum efficiency. This point should be considered for design of a hydrostatic transmission for wind turbine application. The design requirement is to operate the system at its maximum efficiency at the higher input power and as efficient as possible at lower power input. Accordingly, the wind power and turbine characteristics are as follows:

The amount of power that a wind turbine can extract from wind is determined $[11,12]$ as:

$$
P w r=\left(\frac{1}{2} \pi \rho\right) C_{p} R_{\text {blade }} V_{\text {wind }}^{3}, \lambda_{\text {opt }}=\frac{R_{\text {blade }} \omega_{p}}{V_{\text {wind }}}
$$

where $P_{w r}$ is the rotor power, $\rho$ is air density, $C_{p}$ is power coefficient of turbine, $R_{\text {blade }}$ is radius of rotor and $V_{\text {wind }}$ is instantaneous wind speed. $\lambda_{\text {opt }}$ is tip-speed-ratio of the rotor. Considering $T_{\text {rotor }}=P w r \omega_{p}$, the rotor torque can be expressed as a multi-variable function including blade radius, $R_{\text {blade, }}$ as follows:

$$
T_{\text {rotor }}=\left(\frac{1}{2} \pi \rho\right) C_{p}\left(\frac{R_{\text {blade }}^{5}}{\lambda_{\text {opt }}}\right) \omega_{p}^{2} .
$$

The rotor driving torque equals the braking torque applied on the pump shaft as $T_{\text {pump }}=T_{\text {rotor }}$

where $T_{\text {pump }}=\frac{D_{p} P}{\eta_{\text {Pmech }}}$. Hence the pressure is proportional to the square of rotor speed derived as follows:

$$
P=\left(D_{p} \eta_{\text {Pmech }} \frac{1}{2} \pi \rho C_{p} \frac{R_{\text {blade }}^{5}}{\lambda_{\text {opt }}}\right) \omega_{p}^{2} \text {. }
$$

Tracking maximum power point requires maintaining the tipspeed-ratio at its optimum value, $\lambda_{\text {opt }}=\frac{R_{\text {blade }} \omega_{p}}{V_{\text {wind }}}$, thus turbine speed varies linearly with wind speed. While regarding Equation 9, pressure, P., is a quadratic function of turbine 
speed. Considering dimensionless factor $\mathrm{A}, \frac{\mu \omega_{p}}{P}$, at higher wind speeds, the denominator increases faster than the numerator Therefore, factor A becomes smaller. An optimum operation region for a wind turbine is illustrated in Figure 2. In the optimum region, at cut-in speed, the factor $\mathrm{A}$ is large and at high wind speeds it becomes smaller until the rated wind speed where it reaches a point corresponding to the maximum efficiency. By this operation planning, the pump has the best efficiency at the rated power while the condition corresponds to sharp decline in efficiency is avoided. For factor $\mathrm{B}, \frac{\mu \omega_{m}}{P}$, which determines motor efficiency, the numerator is constant since motor speed is maintained regardless of wind speed. Pressure varies quadratically with wind speed, as explained for factor A, thus value of factor B decreases faster at higher wind speed, So that the operation planning of the motor is similar to the pump.

It has been explained that the efficiency of hydrostatic transmission depends on the operating conditions. To achieve higher efficiencies at low wind speeds, the characteristics of the turbine as the prime mover and the generator as the final consumer of the energy must be considered in conjunction with HTS operation characteristics.

\section{EFFICIENCY IMPROVEMENT BY LOWERING GENERATOR SPEED}

To increase the overall energy conversion efficiency, mechanical efficiency, $\eta_{\text {mech }}$, and the volumetric efficiency should be improved. Hydrostatic parameters that affect the efficiency are pressure, pump/motor speeds and displacement. Pump displacement is a constant value but its speed is controlled to maintain the optimum tip-speed-ratio. Thus, these parameters cannot be controlled for efficiency improvement. Effects of motor displacement and pressure can be analyzed to suggest approaches for efficiency improvement.

The efficiency of motor is a strictly increasing function with respect to motor displacement; i.e. larger motor displacement improves the motor efficiency. Partial derivate of a motor efficiency is obtained as follows:

$$
\frac{\partial \eta_{m \text { overall }}}{\partial D_{m}}=\frac{\frac{T_{c m} P}{\left(D_{m} P\right)^{2}}}{\left(1+\frac{K_{S m}}{B}\right)^{2}}>\mathbf{O}
$$

Since the flow rate is determined by pump speed, larger motor displacement reduces motor speed as illustrated by Equation 2. Lower speed of motor which is coupled with the generator means that the generator must have higher number of pole pairs to generate electricity at the grid frequency. In [6], a $1500 \mathrm{rpm}$ generator at $50 \mathrm{~Hz}$ grid frequency was used, [4] used $1800 \mathrm{rpm}$ generator at $60 \mathrm{~Hz}$ grid frequency. These studies demonstrated low efficiency at low wind speeds. Figure 3 illustrates the effect of lower generator speed on the efficiency of the wind energy conversion. To examine what analytically proved, operation of wind turbine with HTS was simulated. Turbine and pump specifications were remained constant throughout simulations. Generator speed was controlled to be constant for each simulation but it changed for different simulations ranging from 600 to $1800 \mathrm{rpm}$. Specifications of the rotor and pump that used for the simulations are summarized in Table I.

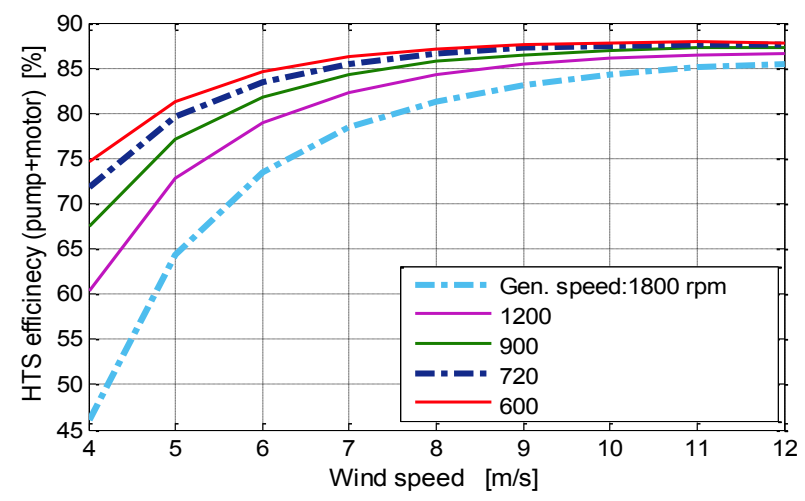

Fig. 3 Effect of generator speed on HTS efficiency

TABLE I.

TURBINE AND PUMP SPECIFICATIONS

\begin{tabular}{|c|c|c|}
\hline \multirow{4}{*}{} & Rated power (kW) & 600 \\
\cline { 2 - 3 } & Diameter (m) & 48 \\
\cline { 2 - 3 } & Maximum power coefficient & 0.475 \\
\cline { 2 - 3 } & Optimum TSR & 7 \\
\hline \multirow{2y}{*}{} & Cut-in speed (m/s) & 4 \\
\cline { 2 - 3 } & Rated wind speed (m/s) & 12 \\
\cline { 2 - 3 } & Displacement (lit/rev) & 43.600 \\
\cline { 2 - 3 } & Max pressure [13] & $10-30$ \\
\hline
\end{tabular}

\section{EFFICIENCY IMPROVEMENT BY INCREASING PRESSURE}

Another approach to increase the efficiency of HTS is to increase the operating pressure specifically at low wind speeds. Increasing driving torque reduces the percentage of torque loss over the driving torque, thus the mechanical efficiency of motor and pump improves. However, this improvement is not always guaranteed since higher pressure reduces the volumetric efficiency. This point can be observed in Figure 2. Considering a constant speed, higher pressures reduce the factor $\mathrm{A}$ in Equation 5. When the pressure induced to a certain value, reduction in volumetric efficiency exceeds the improvement in mechanical efficiency. As a result, the overall efficiency deviates from its maximum point. To ensure that the increasing pressure improves the efficiency, a HTS is designated to operate in optimum region shown in Figure 2. This point is proved analytically for the motor efficiency as follows, similar argument is applied for pump. 


$$
\frac{\partial \eta_{M}}{\partial P}=\frac{\frac{D_{m} \mu \omega_{m} C_{v m}+T_{c m}}{D_{m} P^{2}}+\frac{2 C_{v m} K_{s m}}{P}+\frac{K_{s m}\left(2 T_{c m}+C_{f m}-K_{s m}\right)}{D_{m} \mu \omega_{m} P}}{\left(1+\frac{K_{S m}}{B}\right)^{2}}
$$

Sign of $\frac{\partial \eta_{M}}{\partial P}$ is determined by summation of the three terms in the nominator. The term $\frac{D_{m} \mu \omega_{m} C_{v m}+T_{c m}}{D_{m} P^{2}}$ is always positive but its value is decreased at very high pressure since the denominator increases quadratically with pressure. The term $\frac{2 C_{v m} K_{s m}}{P}$ is also positive. However, the sign of the third term, $\frac{K_{s m}\left(2 T_{c m}+C_{f m}-K_{s m}\right)}{D_{m} \mu \omega_{m} P}$, can be either positive or negative. If the third term is positive, all of terms of the partial derivate are positive and hence the overall efficiency of motor is a strictly increasing function of pressure. However, Breakaway torque, $T_{c m}$, and coulomb friction, $C_{v m}$, are usually smaller than the slippage coefficient, $K_{s m}$ thus the third term of the partial derivate can be negative. As following argument illustrates, from low to medium pressure, the overall efficiency is strictly increasing with pressure.

Low-medium pressure: $\left\{\begin{array}{l}\frac{D_{m} \mu \omega_{m} C_{v m}+T_{c m}}{D_{m} P^{2}}>0 \\ \frac{2 C_{v m} K_{s m}}{P}>0 \\ \frac{K_{s m}\left(2 T_{c m}+C_{f m}-K_{s m}\right)}{D_{m} \mu \omega_{m} P}<0\end{array} \Rightarrow \frac{\partial \eta_{M}}{\partial P}>0\right.$

However, at high pressure:

High pressure: $\left\{\begin{array}{l}\frac{D_{m} \mu \omega_{m} C_{v m}+T_{c m}}{D_{m} P^{2}} \approx 0 \\ \frac{2 C_{v m} K_{s m}}{P}>0 \\ \frac{K_{s m}\left(2 T_{c m}+C_{f m}-K_{s m}\right)}{D_{m} \mu \omega_{m} P}<0\end{array} \quad \Rightarrow \frac{\partial \eta_{M}}{\partial P}<0\right.$

Hence at high pressure, overall efficiency becomes a decreasing function of pressure. From low to medium pressure, the effect of mechanical efficiency overcomes the effect of volumetric efficiency. But at high pressure, effect of volumetric efficiency becomes dominant. The HTS should be designed to operate in the region where efficiency increases at higher pressure.

To increase the pressure at low wind speeds, a sufficient amount of driving turbine torque is required. Based on wind turbine power and torque characteristics, larger swept area generates higher torque, as indicated by Equation 7. Assuming that the wind turbine is designated for a fixed power rating; a turbine with larger swept area reaches its rated power at lower wind speeds. Figure 4 illustrates the correlation between the blade radius, $\mathrm{R}$ and the rated wind speed, and turbine rated power.

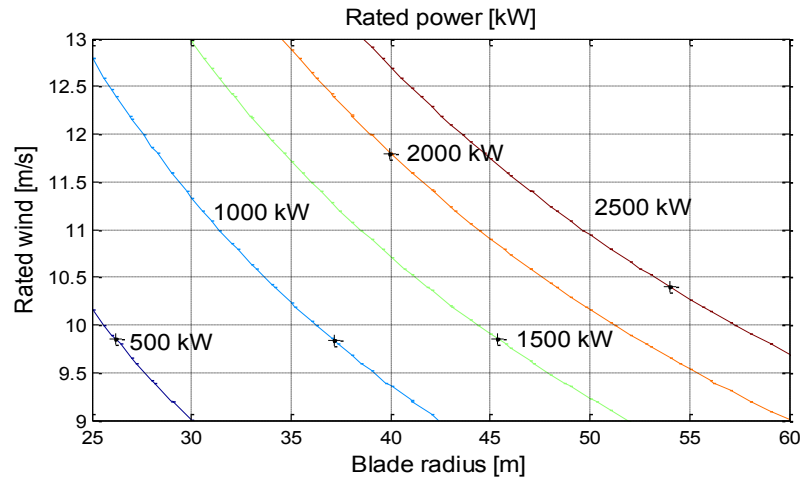

Fig. 4 Power rating at different blade radius and rated wind speed

As Figure 4 demonstrates, different combination of blade radii and rated wind speeds yield the same power rating. Considering Equation 8, the rotor torque is proportional to $R_{\text {blade }}^{5}$. Hence, rotor torque enhancement at low wind speeds is achieved by using larger blades. For instance, the power and torque curve of a wind turbine rated at $600 \mathrm{~kW}$, when utilizing different blade radii, are demonstrated in Figs. 5 and 6.

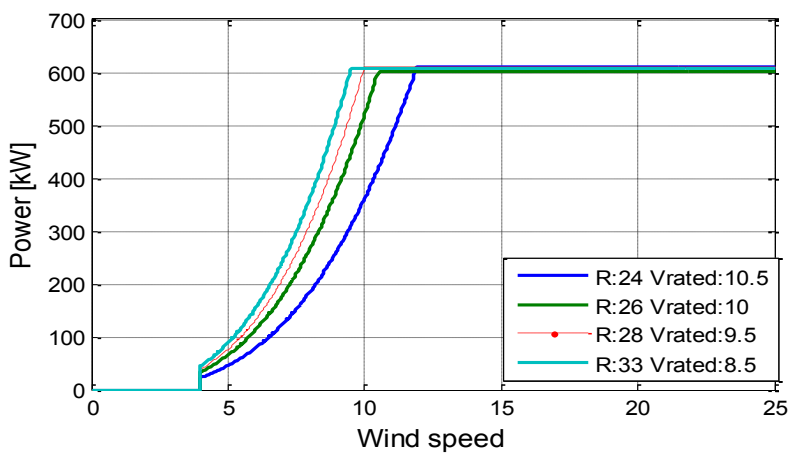

Fig. 5 Power curve of a $600 \mathrm{~kW}$ turbine considering various blade radii

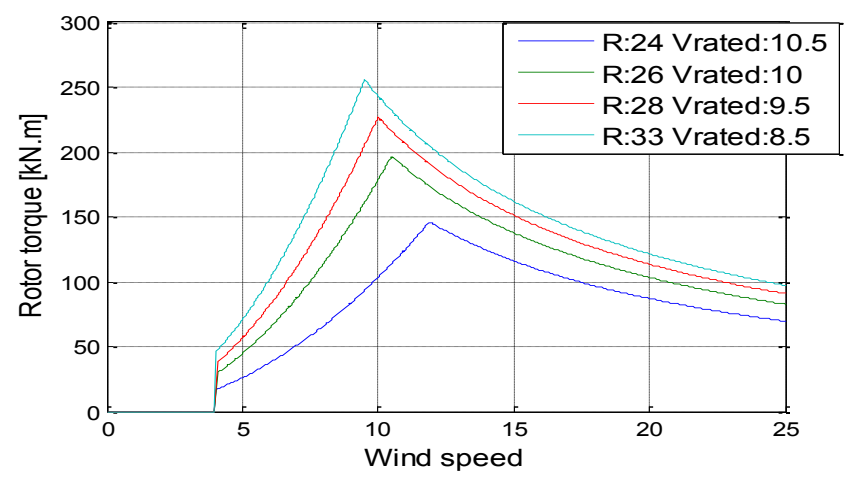

Fig. 6 Torque curve of a $600 \mathrm{~kW}$ turbine considering various blade radii 
As illustrated in Figures 5 and 6, at a specific turbine power rating, a configuration with larger blade radius generates higher torque at lower wind speed. Higher torque enables the pump and motor to have higher pressure and consequently, the efficiency of the WT with HTS improves. For verification, the operation of a wind turbine with different combination of blade radii and rated wind speeds are simulated.

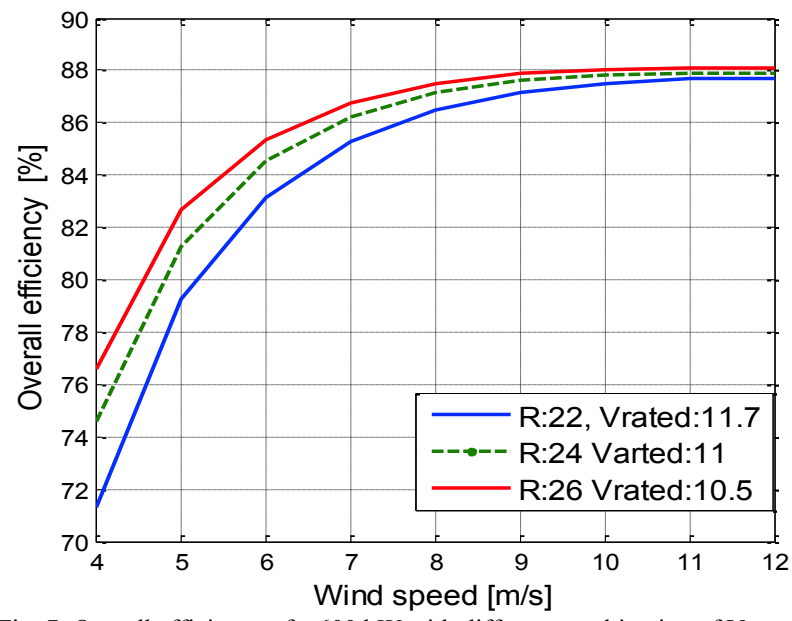

Fig. 7 Overall efficiency of a $600 \mathrm{~kW}$ with different combination of Vrated and blade radius.

It can be observed from Figure 7 that at a defined power rating, a configuration that has longer blade yields higher efficiency especially at lower wind speeds.

\section{ANNUAL ENGERy PRODUCTION}

One important metric to evaluate the performance of a wind turbine is its annual energy production (AEP) [3, 11, 14]. AEP estimates the energy production from a wind turbine applying power curve of the WT considering a wind speed probability distribution over a year at the wind turbine site $[15$, 16]. Wind speed profile is assumed to follow Weibull distribution and, depending on mean wind speed, its scale factor varies while the shape factor is usually around $2[17$, 18]. The probability associated to each wind speed resulted from various annual mean wind speed is shown in Figure 8. Performance of the proposed HTS is compared with the geared counterparts. The rotor specifications/dimensions used for both wind turbines are identical. Their AEP were compared at different annual mean wind speeds. At each annual mean wind speed, the same scale factor and shape factor applied on a both plants. The wind speed turbulence is not accounted in AEP calculation. Furthermore, to investigate the effect of swept area, AEP for two other WTs utilizing HTS with larger swept areas were compared with the geared counterparts. The comparisons were performed at two power rating range, one for $750-900 \mathrm{~kW}$ and the one for $1500-1700$ $\mathrm{kW}$. The rotors specifications and the power curves of conventional turbine that used for the comparison are listed in Table II $[19,20]$. Figures 9-10 illustrate the results of the comparisons
TABLE II.

SPECIFICATIONS OF THREE TURBINES USED FOR AEP COMPARISON 750-900 KW WIND TURBINES

\begin{tabular}{|c|c|c|}
\hline $\begin{array}{c}\text { Rotor Radius } \\
(\mathbf{m})\end{array}$ & Specification & Value \\
\hline \multirow{3}{*}{26} & Power coefficient & 0.468 \\
\cline { 2 - 3 } & Cut-in speed & 4 \\
\cline { 2 - 3 } & Rated speed & 11.7 \\
\hline \multirow{3}{*}{29} & Power coefficient & 0.487 \\
\cline { 2 - 3 } & Cut-in speed & 4 \\
\cline { 2 - 3 } & Rated speed & 11 \\
\hline \multirow{3}{*}{32} & Power coefficient & 0.482 \\
\cline { 2 - 3 } & Cut-in speed & 4 \\
\cline { 2 - 3 } & Rated speed & 11 \\
\hline
\end{tabular}

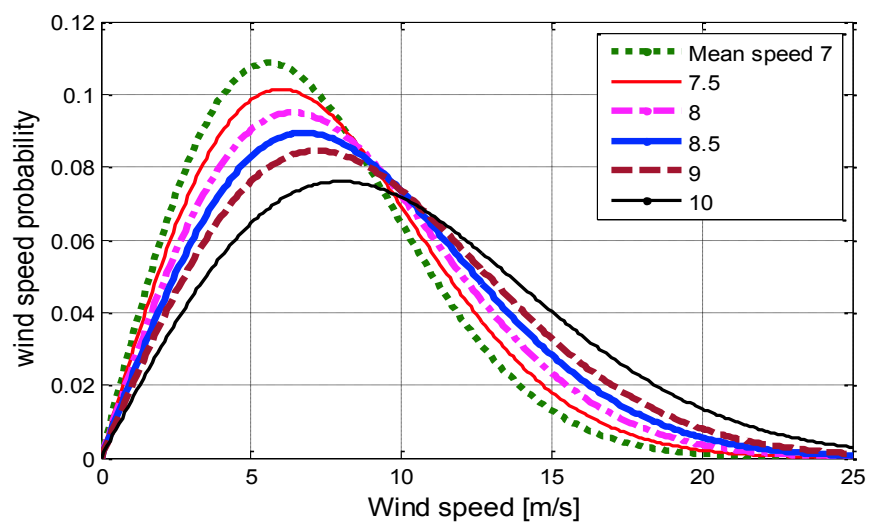

Fig. 8 Wind speed probability at different mean wind speed

An important factor that determines the energy production is probability wind speed over a long period. Figure 8 illustrates probability distribution function, PDF, for different mean wind speeds. A Wind turbine is designated to operate at a site where the annual wind speed is known. However, for the analysis purpose, AEP of HTS and conventional wind turbines were compared at different annual wind speeds.

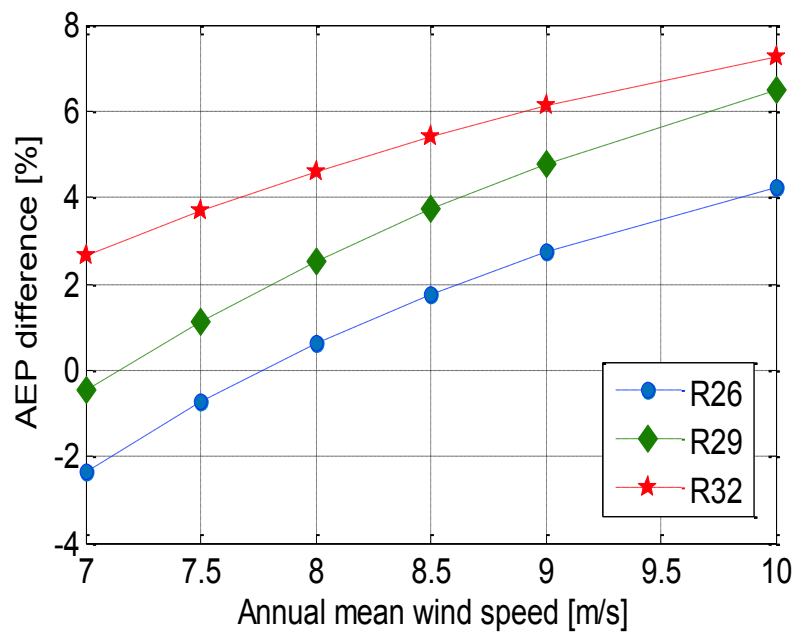

Fig. 9 AEP improvement of a HTS compared with a conventional WT, power rating: $750-900 \mathrm{~kW}$ 
Figure 9 demonstrates that a HTSWT with rotor radius of 32 meter generates in average 3-7 percent higher energy than a conventional counterpart. Similarly, a HTSWT with radius of 29 meter yields 0-6 percent higher energy than a conventional wind turbine. For a turbine at radius of 26 meter, at low mean wind speed up to $7.7 \mathrm{~m} / \mathrm{s}$ a HTSWT generates less energy than a conventional WT while at higher wind speed, HTSWT produces higher energy. Also, comparing the trend of AEP difference variation with respect to the radius, it is observed that larger rotor radius improves energy production of a HTSWT.

Similar simulation comparisons were performed on greater power rating in the range of $1500-1700 \mathrm{~kW}$. Three rotor sizes were used to calculate their AEP under wind speed probability with shape factor 2 . The scale factor varies according to each annual mean wind speed. Table III provides specifications for the rotors used in this comparison.

TABLE III.

SPECIFICATIONS OF THREE TURBINES USED FOR AEP COMPARISON 1500$1700 \mathrm{KW}$ WIND TURBINES

\begin{tabular}{|c|c|c|}
\hline $\begin{array}{c}\text { Rotor radius } \\
(\mathbf{m})\end{array}$ & Specification & Value \\
\hline \multirow{3}{*}{35} & Power coefficient & 0.461 \\
\cline { 2 - 3 } & Cut-in speed & 3.5 \\
\cline { 2 - 3 } & Rated speed & 12.7 \\
\hline \multirow{3}{*}{38.5} & Power coefficient & 0.459 \\
\cline { 2 - 3 } & Cut-in speed & 3.5 \\
\cline { 2 - 3 } & Rated speed & 12 \\
\hline \multirow{3}{*}{41.2} & Power coefficient & 0.482 \\
\cline { 2 - 3 } & Cut-in speed & 3.5 \\
\cline { 2 - 3 } & Rated speed & 11.4 \\
\hline
\end{tabular}

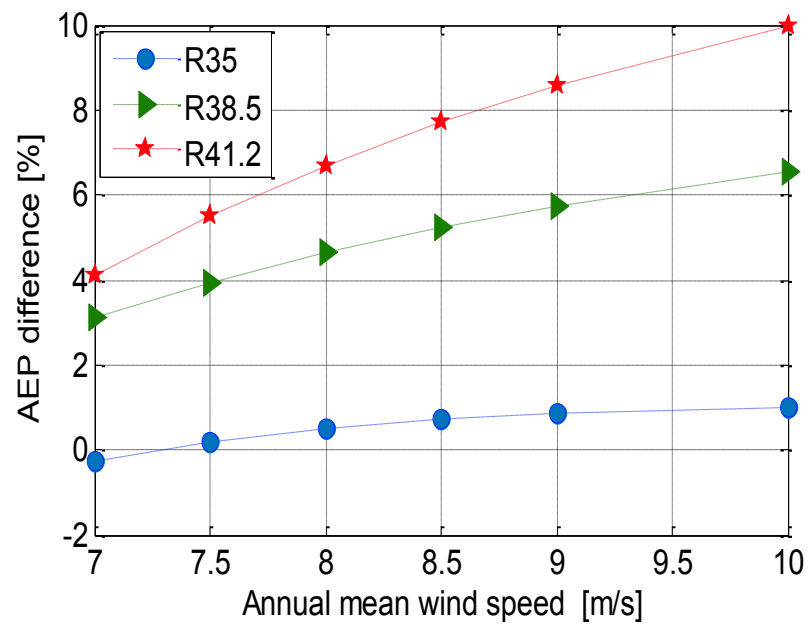

Fig. 10 AEP improvement of a HTSWT compared with a conventional WT, power rating: $1500-1700 \mathrm{~kW}$

Comparisons of AEP difference between HTSWT and conventional wind turbines presented in Figure 10 follow similar trends that were explained for Figure 9.

As seen on Figures 9 and 10 the AEP difference between a HTSTW and a geared WT increases in favor of HSTWT at higher annual mean wind speeds. The reasoning for this observation can be explained as follows:

Conventional wind turbine using induction generators have maximum speed limitation. In these wind turbines, the generator load torque controls the generator speed to track maximum wind power. At wind speeds near rated, the optimum generator speed exceeds maximum generator speed therefore, the rotor power coefficient is derated which causes the rotor reach its power rating at wind speed higher than its theoretical value. This point has been shown in [21]. However, in a HTSWT, since the generator and rotor are decoupled, rotor speed follows maximum wind power at any wind speed below the rated value. Thus, using the identical rotor, at high wind speed, a HTSWT's power is greater than a conventional turbine's power. When annual mean wind speed increases, the probability of higher wind speed increases thus a HTSWT can yields higher energy annually.

\section{CONCLUSION}

In this study, sources of power losses within hydrostatic pump and motor were identified. Efficiency improvements approaches were analytically investigated. Various characteristics of wind turbines were considered to implement those approaches. It has been demonstrated that planning operation of the pump and motor in the optimum region, using larger blade radius and lowering generator speed enhance efficiency. Simulated annual energy production of HTS wind turbines and conventional turbine demonstrated that larger blade radii yield higher AEP. In addition, it was observed that an optimally designed HTSWT can generate higher energy than that of a conventional turbine and that the difference in energy production becomes higher at higher annual mean wind speeds.

\section{REFERENCES}

[1] A. Izadian, N. Girrens, and P. Khayyer, "Renewable energy policies: A brief review of the latest US and EU policies," Industrial Electronics Magazine, IEEE, vol. 7, pp. 21-34, 2013.

[2] S. Sheng, "Report on Wind Turbine Subsystem Reliability-A Survey of Various Databases," NREL/PR-5000-59111. Golden, CO: National Renewable Energy Laboratory2013.

[3] S. Tegen, M. Hand, B. Maples, E. Lantz, P. Schwabe, and A. Smith, "2011 Cost of wind energy review," Golden, CO: National Renewable Energy Laboratory, 2013.

[4] B. Thul, R. Dutta, and K. A. Stelson, "Hydrostatic Transmission for Mid-Size Wind Turbines," in Proceedings of 52nd National Conference on Fluid Power, Las Vegas, NV, 2011.

[5] J. Schmitz, N. Diepeveen, N. Vatiieuer, and H. Murrenhoff, "Dynamic Transmission Response of a Hydrostatic Transmission measured on a Test Bench," 2012.

[6] J. Schmitz, N. Vatheuer, and H. Murrenhoff, "Hydrostatic drive train in wind energy plants," 
RWTH Aachen University, IFAS Aachen, Germany, 2011.

[7] R. Dutta, F. Wang, B. F. Bohlmann, and K. A. Stelson, "Analysis of Short-Term Energy Storage for Midsize Hydrostatic Wind Turbine," Journal of Dynamic Systems, Measurement, and Control, vol. 136, p. 011007, 2014.

[8] E. C. Fitch, Hydraulic component design and selection: Bardyne. Incorporated, 2004.

[9] N. Manring, Hydraulic control systems: John Wiley \& Sons Incorporated, 2005.

[10] H. E. Merritt, Hydraulic control systems: J. Wiley, 1967.

[11] S. N. Bhadra, D. Kastha, and S. Banerjee, Wind electrical systems: Oxford University Press, 2005.

[12] F. D. Bianchi, H. De Battista, and R. J. Mantz, Wind turbine control systems: principles, modelling and gain scheduling design: Springer, 2006.

[13] J. A. Baroudi, V. Dinavahi, and A. M. Knight, "A review of power converter topologies for wind generators," Renewable Energy, vol. 32, pp. 23692385, 2007.

[14] A. N. Celik, "Energy output estimation for smallscale wind power generators using Weibullrepresentative wind data," Journal of Wind
Engineering and Industrial Aerodynamics, vol. 91, pp. 693-707, 2003.

[15] G. L. Johnson, Wind energy systems: Gary L. Johnson, 2006.

[16] P. Nielsen and T. SORSEN, "WindPRO software user manual," Alborg, Denmark, EMD International $A S$, vol. 181, 2006.

[17] D. W. I. Association. (2014, 10/29). Available: http://www.motiva.fi/myllarin tuulivoima/windpowe r\%20web/en/tour/wres/pow/index.htm

[18] T. Burton, N. Jenkins, D. Sharpe, and E. Bossanyi, Wind energy handbook: John Wiley \& Sons, 2011.

[19] C. Carrillo, A. O. Montaño, J. Cidrás, and E. DíazDorado, "Review of power curve modelling for wind turbines," Renewable and Sustainable Energy Reviews, vol. 21, pp. 572-581, 2013.

[20] G. S. Matthew West, Kurt Myers, "Excel Wind Analysis Program," ed. Idaho National Engineering and Enviornment Laboratory Idaho National Laboraty 2005

[21] J. M. Jonkman, S. Butterfield, W. Musial, and G. Scott, Definition of a 5-MW reference wind turbine for offshore system development: National Renewable Energy Laboratory Golden, CO, 2009. 